\title{
Re: Lundar T, Due-Tønnessen BJ, Frič R, Brandal P, Stensvold E, Due-Tønnessen P. Outcomes in adulthood after neurosurgical treatment of brain tumors in the first 3 years of life: long-term follow-up of a single consecutive institutional series of 97 patients. Childs Nerv Syst. 2021 Feb;37 (2):427-433
}

\author{
P. Steinbok ${ }^{1}$ (D) S. Pillai ${ }^{2}$ \\ Received: 27 February 2021 / Accepted: 2 March 2021 / Published online: 8 March 2021 \\ (C) The Author(s), under exclusive licence to Springer-Verlag GmbH Germany, part of Springer Nature 2021
}

Dear Editor,

We compliment Lundar et al. [1] on their important report of functional outcomes more than 20 years after treatment of neurosurgical treatment of brain tumors in the 1 st 3 years of life. Pillai et al. [2] reported a somewhat similar assessment of functional outcomes in children treated for brain tumors in the first year of life, followed for a minimum of 5 years after surgery. In this series, the patients who survived $>5$ years ranged from 6 to 25 years of age at the time of last followup. In this report, $34 \%$ of the infants diagnosed with brain tumors had a good functional outcome and $28 \%$ were able to attend regular school or take up a skilled job. Histological grade of tumor was the only independent predictor associated with outcome.

We were surprised and disappointed that Lundar et al. [1] omitted to cite this report, which is one of the most pertinent to their study. Indeed, on a PubMed search for "long-term outcomes after brain tumor in infants," this article by Pillai et al. [2] came up as \#6 when using the "best match" display option.

Perhaps there is a legitimate explanation for this omission, but we do hope that authors take more care, as is ethically

P. Steinbok

psteinbok@cw.bc.ca

1 Division of Neurosurgery and Department of Surgery, BC Children's Hospital and University of British Columbia, 4750 Hudson Street, Vancouver, BC V6H 3C2, Canada

2 Department of Neurosurgery, Narayana Institute of Neuroscience, Bangalore, India required, to review and cite relevant prior publications when writing a scientific article for publication [3].

\section{Declarations}

Conflict of interest On behalf of all authors, the corresponding author states that there is no conflict of interest.

\section{References}

1. Lundar T, Due-Tønnessen BJ, Frič R, Brandal P, Stensvold E, DueTønnessen P (2021) Outcomes in adulthood after neurosurgical treatment of brain tumors in the first 3 years of life: long-term follow-up of a single consecutive institutional series of 97 patients. Childs Nerv Syst 37:427-433

2. Pillai S, Metrie M, Dunham C, Sargent M, Hukin J, Steinbok P (2012) Intracranial tumors in infants: long-term functional outcome, survival, and its predictors. Childs Nerv Syst 28:547-555

3. Steinbok P (1995) Ethical considerations relating to writing a medical scientific paper for publication. Childs Nerv Syst 11:323-328

Publisher's note Springer Nature remains neutral with regard to jurisdictional claims in published maps and institutional affiliations. 